\section{Spontaneous Rupture of Uterus at 22 Weeks' Pregnancy}

Brit. med. F., 1967, 3, 844

\section{CASE REPORT}

The patient, a woman of 35 , had had no children after 11 years of marriage. In January 1966, when 22 weeks pregnant, her uterus ruptured spontaneously. At operation twin foetal sacs were found free in the peritoneal cavity.

Her previous gynaecological history was complicated. A year before the uterus ruptured, after 10 weeks' amenorrhoea, she was said to have passed grape-like tissue during a vaginal bleed. Microscopy was not carried out, and this tissue was presumed to be hydatidiform mole. During the next four months she had intermittent episodes of vaginal bleeding but no proper period. A diagnostic curettage was therefore done, when fresh products of conception were evacuated; she continued to bleed, and eight days later a further curettage had to be performed. At this operation the uterus was perforated. Shortly afterwards she had a normal period.

Five months later she presented with amenorrhoea of 14 weeks' duration, and a pregnancy consistent with 18 weeks' gestation was felt. This proceeded normally, apart from the discrepancy between the uterine size and period of amenorrhoea.

The day after a visit to the antenatal clinic at 22 weeks she was admitted complaining of sudden and severe abdominal pain, with vaginal bleeding. There was no history of trauma or uterine contractions. On examination there were no signs of circulatory collapse. The abdomen was distended, with tenderness all over. The uterus could not be delineated either abdominally or per vaginam. There was some vaginal blood loss.

A diagnosis was made of intraperitoneal bleeding from either ruptured uterus or ectopic pregnancy. At laparotomy twin foetal sacs, each about the size of a 22-week pregnancy, were found free in the peritoneal cavity, which contained about $750 \mathrm{ml}$. of blood. The uterus had contracted to the size of a 16-week pregnancy, and in the midline of the fundus was a tear through which a finger could be passed. The foetal sacs and blood were removed, and, since the patient had had no children, a simple suture of the tear was performed.

\section{Diaphysial Aclasia with Compression of the Spinal Cord}

\section{Brit. med.F., 1967, 3, 844-845}

In their review of 1,102 patients with diaphysial aclasia Stocks and Barrington (1925) found that only 7\% had vertebral osteochondromata. If these occur within the spinal canal they can cause compression of the spinal cord or the cauda equina. The first case was described by Ochsner and Rothstein (1907), but since then very few cases have been recorded. Slepian and Hamby (1951) could find only nine certain cases of cord compression. They added a further case, and three more cases have been reported (Cannon, 1954 ; Gokay and Bucy, 1955 ; Larson, Dodge, Rushton, and Dahlin, 1957). This makes a total of 13 cases, and, since diaphysial aclasia is not a very rare condition (Jaffe, 1958), cord compression is an unusual complication.

\section{CASE REPORT}

A schoolgirl aged 16 presented with a sudden onset of clumsiness of the right hand, which rapidly increased. This was followed a month later by weakness of the right knee.
Her recovery was normal. A hysterogram six months later showed a small filling defect in the fundus. In September 1967 the patient was 30 weeks pregnant, and so far all was well.

\section{COMMENT}

Rupture of the pregnant uterus before the onset of contractions of labour or abortion is rare. Published reports are few. The above case presented the combination of twin pregnancy with a previous uterine perforation and possible hydatidiform mole. The largest collection of spontaneous rupture of the apparently normal uterus is that of Felmus et al. (1953). Of their 121 cases a quarter had had previous uterine instrumentation. In three cases trophoblastic invasion of the myometrium was given as the immediate predisposing cause. One-third of their cases ruptured before the sixth month of gestation. In the above case the uterus had ruptured in the midline of the fundus, where a perforation would most likely be. Characteristically, the pregnant uterus ruptures through the body; the uterus in labour ruptures through the lower segment.

It is unusual for the foetus to be extruded completely through the rupture. In the present case both sacs were free in the peritoneal cavity. Because of this the uterus had been allowed to retract and thereby diminish the extent of the tear. This probably lessened the bleeding and would explain the patient's good general condition. Most reports describe the patient as being shocked.

The treatment of choice is hysterectomy, the subtotal operation being done if speed is necessary. Two cases of repeated rupture of the uterus in a subsequent pregnancy have been described after simple suture of the tear (Lazarević, 1932 ; Wenner, 1949).

I would like to thank Miss Lois E. Hurter for permission to publish this case.

\section{E. R. BATEMAN, F.R.C.S., M.R.C.o.G.,} St. Thomas's Hospital, London S.E.1.

\section{REFERENCES}

Felmus, L. B., Pedowitz, P., and Nassberg, S. (1953). Obstet. gymec. Surv., 8, is5.

Lazarevic,, V. (1932). Zlb. Gynäk., 56, 1291. Wenner, R. (1949). Gynaecologia (Basel), 128, 38.

On examination she had typical generalized diaphysial aclasia. The neurological examination showed wasting and weakness of the intrinsic muscles of both hands and weakness of the flexors and extensors of the right elbow and wrist. Abduction and adduction of the right shoulder were also weak. The reflexes in the right arm were weak or absent. There was a mild spastic paresis of the right leg, but both plantar responses were flexor. There were no abnormal sensory signs apart from poor position sense in the fourth and fifth fingers of the right hand.

Investigations.-Radiographs of the cervical spine, including tomograms, showed exostoses arising from the spinous processes and laminae of the fifth and sixth cervical vertebrae (Fig. 1). A myelogram showed a posterior filling defect at the level of the fifth cervical vertebra (Fig. 2). Lumbar puncture showed nothing abnormal apart from a protein of $58 \mathrm{mg} . / 100 \mathrm{ml}$.

Operation.-Exostoses were found on the back of both the laminae of the fifth cervical vertebra. A laminectomy of the fifth and sixth cervical vertebrae was performed and two exostoses were found on the front of the lamina of the fifth cervical vertebra $(0.5$ and $0.75 \mathrm{~cm}$. in diameter) and one larger exostosis $(1 \mathrm{~cm}$. in diameter) on the front of the lamina of the sixth cervical vertebra. These were indenting the dura mater. Histology showed that they were typical osteochondromata.

After operation she developed retention of urine, which cleared within three weeks, and a month after operation she had almost normal power in all four limbs. During the next year she had intermittent episodes of mild weakness of the right leg and both 